УДК 616.89-441.13:159.938.252:575.174.015.3:616-072.8

Для цитирования: Савочкина Д.Н., Полтавская Е.Г. Оценка психофизиологических характеристик и полиморфизма гена SCN9A при формировании аддиктивного поведения. Сибирский вестник психиатрии и наркологии. 2018; 4 (101): 11-15. https://doi.org/10.26617/1810-3111-2018-4(101)-11-15

\title{
Оценка психофизиологических характеристик и полиморфизма гена SCN9A при формировании аддиктивного поведения
}

\section{Савочкина Д.Н., Полтавская Е.Г.}

Научно-исследовательский институт психического здоровья, Томский национальный исследовательский медицинский центр Российской академии наук (НИИ психического здоровья Томский НИМЦ) Россия, 634014, Томск, ул. Алеутская, 4

\section{PЕЗЮМЕ}

В данной работе анализировались взаимосвязи показателей болевой чувствительности, гендерной самоидентификации и генетических особенностей обследуемых лиц на разных этапах формирования аддиктивного поведения. Материалы и методы. В исследование было включено 248 человек: 108 пациентов с зависимостью от психоактивных веществ (ПАВ), 34 человека из группы риска, 106 человек контрольной группы. С помощью вопросника Сандры Бэм определялся гендерный индекс и выявлялась направленность гендерной самоидентификации. Пороги болевой чувствительности и переносимость боли определялись с помощью запатентованного нами метода тензоалгометрии. Генотипирование полиморфного варианта rs6746030 гена SCN9A проводили методом ПЦР в реальном времени с использованием конкурирующих TaqMan-зондов. Результаты. Лица женского пола с психическими и поведенческими расстройствами, вызванными употреблением психоактивных веществ, характеризуются снижением выраженности фемининной направленности гендерной самоидентификации. Показана взаимосвязь гендерной самоидентификации и болевой чувствительности у зависимых от ПАВ лиц: для более высоких значений нижнего болевого порога было характерно снижение выраженности фемининности у женщин и маскулинности у мужчин. В группе мужчин, зависимых от ПАВ, нижний болевой порог был значимо выше, чем в контрольной группе. Выявлены корреляции значений нижнего болевого порога со стажем зависимости у мужчин и у женщин, а также с переносимостью боли в группе женщин. Заключение. На уровне статистической тенденции была выявлена ассоциация генотипа AG rs6746030 гена SCN9A с переносимостью боли и с развитием зависимости от ПАВ в группе женщин.

Ключевые слова: rs6746030 гена SCN9A, болевая чувствительность, гендерная самоидентификация, зависимость от психоактивных веществ.

\section{ВВЕДЕНИЕ}

Гендерная идентичность предполагает самоидентификацию с определенным полом, единство сознания и поведения индивида, относящего себя к тому или иному полу. В процессе своего становления гендерная идентичность проходит ряд этапов, соотносимых с возрастными этапами психического и физиологического развития человека. Формирование аддиктивного поведения [1] оказывает воздействие в том числе и на гендерную самоидентификацию. Показана связь между алкогольной и никотиновой зависимостями и гендерными стереотипами юношей и девушек [2]. Отмечается, что для подростков, имеющих опыт употребления каннабиноидов, характерна слабая дифференцированность представлений о маскулинности/фемининности, индифферентное отношение к гендерной принадлежности [3, 4]. Естественные адаптационные возможности аддикта нарушены на психофизиологическом уровне. Длительное употребление опиоидов приводит к повышению болевой чувствительности возникновению опиоидно-индуцированной гипералгезии.

Индивидуальные различия болевого ответа [5] используются в качестве инструмента исследования ноцицептивных механизмов и рассматриваются как основа для персонализированного подхода к боли. Множество факторов, модулирующих боль, предпо- лагает сравнительную оценку их влияния на восприятие боли.

Значительный вклад в индивидуальные различия болевой чувствительности вносят генетические факторы [6]. Было показано, что полиморфизм rs6746030 гена SCN9A, который характеризуется аминокислотной заменой R1150W, может влиять на болевую чувствительность, изменяя потенциал покоя в NaV1.7 [7]. Мутации в гене SCN9A связывали с синдромами как сниженного, так и повышенного восприятия боли [8].

\section{ЦЕЛЬ ИССЛЕДОВАНИЯ}

Установление взаимосвязей гендерной самоидентификации, параметров ноцицепции и полиморфизма гена SLC9A у лиц на разных этапах формирования аддиктивных расстройств.

\section{МАТЕРИАЛЫ И МЕТОДЫ}

В исследование было включено 248 человек

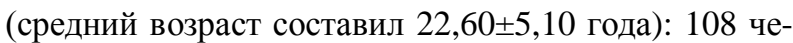
ловек с психическими и поведенческими расстройствами, вызванными употреблением психоактивных веществ (наркологические пациенты) (из них 48 мужчин и 60 женщин), 106 условно здоровых лиц (контрольная группа) (88 мужчин и 18 женщин), 34 человека, эпизодически и случайно употребляющие психоактивные вещества, согласно классификации Э.Е. Бехтеля (группа риска) (из них 16 мужчин и 18 женщин). 
Исследование проводилось на базе отделения аддиктивных состояний клиники НИИ психического здоровья Томского НИМЦ, лаборатории клинической психонейроиммунологии и нейробиологии и лаборатории молекулярной генетики и биохимии НИИ психического здоровья Томского НИМЦ. Формирование групп обследованных также проходило на базе Томского областного наркологического диспансера, Кемеровского областного наркологического диспансера. Контрольную группу составили студенты средних специальных и высших учебных заведений. Обследование проведено с соблюдением принципов Хельсинкской декларации Всемирной медицинской ассоциации. Клиническая верификация осуществлялась психиатрами-наркологами в соответствии с Международной классификацией болезней 10-го пересмотра (МКБ-10), диагноз квалифицировался как «Психические и поведенческие расстройства, вызванные употреблением психоактивных веществ» шифр (F1): употребление с вредными последствиями (F1x.l) и синдром зависимости (F1x.2).

Оценка порогов болевой чувствительности осуществлялась с помощью запатентованного нами собственного метода тензоалгометрии, который позволяет оценить пороги болевой чувствительности - минимальное болевое ощущение, которое субъект в состоянии распознать (нижний болевой порог), а также порог переносимости боли (верхний болевой порог) [9]. Результаты тензоалгометрии оценивались в условных единицах (усл. ед.). Для оценки эмоционального отношения к боли была использована визуально-аналоговая шкала [10]. С помощью вопросника Сандры Бэм по изучению маскулинности - фемининности определялся гендерный индекс и выявлялась направленность гендерной самоидентификации. Значения гендерного индекса >0 квалифицировались как фемининная направленность гендера, $<0$ - как маскулинная, $=0$ как отсутствие гендерной самоидентификации [11]. Генотипирование полиморфного варианта гена SCN9A (rs6746030) проводили методом ПЦР в реальном времени на амплификаторе Step One Plus TM Real-Time PCR System (Applied Biosystems, CШA) c использованием наборов TaqMan Validated SNP Genotyping Assay (Applied Biosystems, США).

Статистический анализ данных проводился с использованием программы SPSS 21.0. Использовались непараметрические критерии КраскелаУоллиса, Манна-Уитни. Для сравнения качественных признаков применялся критерий $\chi^{2}$.

\section{РЕЗУЛЬТАТЫ и ОБСУЖДЕНИЕ}

Результаты исследования ноцицепции и гендерной самоидентификации в обследованных группах представлены в таблице 1.

У мужчин из группы зависимых от ПАВ показатель нижнего болевого порога был статистически значимо выше, чем в контрольной группе. Из таблицы 1 также видно, что, несмотря на отсутствие статистических различий, в группе лиц, эпизодически употребляющих ПАВ, данный показатель для мужчин был выше, чем в группе здоровых лиц. Для женщин показатель гендерного индекса статистически значимо различался: в группах наркологических пациентов и лиц с эпизодическим употреблением ПАВ он был ниже, чем в контрольной группе, то есть для женщин, употребляющих ПАВ, было характерно снижение выраженности фемининности.

Т а б ли и а

Ноцицептивные параметры и гендерный индекс в группах сравнения Median (LQ; UQ)

\begin{tabular}{|c|c|c|c|}
\hline Показатель & Контрольная группа & Группа риска & Наркологические пациенты \\
\hline $\begin{array}{l}\text { Переносимость боли по ВАШ, усл. ед. } \\
\text { Мужчины } \\
\text { Женщины }\end{array}$ & $\begin{array}{l}6,0(5,5-7,0) \\
6,0(4,65-6,0)\end{array}$ & $\begin{array}{c}6,0(4,0-6,65) \\
4,0(3,0-6,0)\end{array}$ & $\begin{array}{c}6,0(3,0-6,75) \\
6,0(5,0-7,0) \\
\end{array}$ \\
\hline $\begin{array}{lc}\text { Мужчины } & \text { БН, усл. ед. } \\
\text { Женщины } & \\
\end{array}$ & $\begin{array}{l}5,0(3,5-7,5) \\
6,0(4,0-8,5)\end{array}$ & $\begin{array}{c}9,0(7,0-10,0) \\
5,0(4,0-7,0)\end{array}$ & $\begin{array}{c}8,0(5,5-11,0)^{* *} \\
4,0(2,0-4,0)\end{array}$ \\
\hline $\begin{array}{ll}\text { Мужчины } & \text { БВ, усл. ед. } \\
\text { Женщины } & \\
\end{array}$ & $\begin{array}{l}15,0(12,5-16,0) \\
12,0(10,0-14,0)\end{array}$ & $\begin{array}{l}15,0(13,5-16,0) \\
12,0(11,0-12,0)\end{array}$ & $\begin{array}{c}15,0(14,5-15,0) \\
11,0(7,0-14,0)\end{array}$ \\
\hline $\begin{array}{l}\quad \text { Гендерный индекс, баллы } \\
\text { Мужчины } \\
\text { Женщины }\end{array}$ & $\begin{array}{c}-0,043(-1,611-0,011) \\
0,279(0,065-1,045)\end{array}$ & $\begin{array}{l}-0,097(-0,216-0,097) \\
0,065(-0,065-0,086)^{*}\end{array}$ & $\begin{array}{c}-0,011(-0,140-0,012) \\
0,022(-0,014-0,086)^{*}\end{array}$ \\
\hline
\end{tabular}

П р и м е ч а н и е: * - p<0,05 при сравнении с контрольной группой; ** - p<0,001 при сравнении с контрольной группой.

При дальнейшем статистическом анализе данных была выявлена корреляция гендерного индекса со значением нижнего болевого порога в группе мужчин на уровне статистической значимости $(\mathrm{p}=0,016)$, а в группе женщин на уровне статистической тенденции $(\mathrm{p}=0,104)$. При этом если в группе мужчин выявлена прямая корреляция данных показателей, то в группе женщин обратная, то есть в группе мужчин повышение нижнего болевого порога соответствовало снижению значения гендерного индекса (снижению маскулинности), а в группе женщин его повышению (снижению фемининности). Таким образом, можно предположить, что высокое значение нижнего болевого порога ассоциировалось с потерей гендерной самоидентификации, при которой гендерный индекс близок к нулю.

Также анализ данных показал, что в группе мужчин с показателем нижнего болевого порога коррелирует стаж употребления ПАВ $(\mathrm{p}=0,039)$. Так, чем больше был стаж у зависимых от ПАВ мужчин, тем 
ниже был нижний болевой порог. В группе женщин стаж коррелировал с восприятием болевых ощущений $(\mathrm{p}=0,018)$. Чем больше был стаж употребления ПАВ у женщин с зависимостью, тем ниже был показатель переносимости боли по ВАШ, то есть чувствительность к боли была снижена.
При исследовании генетических особенностей обследованных лиц в группах сравнения были проанализированы частоты распределения генотипов и аллелей полиморфизма rs6746030 гена SCN9A. Результаты данного анализа приведены в таблице 2.

Распределение частот генотипов и аллелей rs6746030 гена SCN9A у лиц, зависимых от ПАВ, из группы риска и контрольной группы

Т а б ли ц а 2

\begin{tabular}{|c|c|c|c|c|c|c|}
\hline \multicolumn{7}{|c|}{$\begin{array}{c}\text { Распределение частот генотипов и аллелей rs6746030 гена SCN9A у лиц, } \\
\text { зависимых от ПАВ, из группы риска и контрольной группы }\end{array}$} \\
\hline \multirow[t]{2}{*}{ Группа } & \multicolumn{3}{|c|}{ Генотипы } & \multicolumn{2}{|c|}{ Аллели } & Критерий $\chi^{2}$, \\
\hline & GG & $\mathrm{AG}$ & AA & $\mathrm{G}$ & A & 2,656 \\
\hline Контрольная & $82(75,9 \%)$ & $23(21,3 \%)$ & $3(2,8 \%)$ & $187(86,6 \%)$ & $29(13,4 \%)$ & $\mathrm{p}=0,617$ \\
\hline Группа риска & $28(82,4 \%)$ & $5(14,7 \%)$ & $1(2,9 \%)$ & $61(89,7 \%)$ & $7(10,3 \%)$ & \\
\hline Наркологические пациенты & $74(69,8 \%)$ & $29(27,4 \%)$ & $3(2,8 \%)$ & $177(83,5 \%)$ & $35(16,5 \%)$ & \\
\hline
\end{tabular}

Распределение частот генотипов исследуемого полиморфного варианта гена SCN9A во всех трех группах соответствовало равновесию ХардиВайнберга. Статистически значимых различий между группами выявлено не было.

В исследовании мы проводили анализ данных в общей группе обследованных лиц, а также в подгруппах женщин и мужчин. В группе мужчин различий выявлено не было $\left(\chi^{2}=1,676, \mathrm{p}=0,795\right)$. В то время как в группе женщин распределение генотипов исследуемого локуса статистически значимо различалось между группами (табл. 3).

Т а бл и ц а 3

Распределение частот генотипов и аллелей rs6746030 гена SCN9A у женщин, зависимых от ПАВ, из группы риска и контрольной группы

\begin{tabular}{|c|c|c|c|c|c|c|}
\hline \multirow[t]{2}{*}{ Группа } & \multicolumn{3}{|c|}{ Генотипы } & \multicolumn{2}{|c|}{ Аллели } & Критерий $\chi^{2}$, \\
\hline & GG & AG & AA & G & A & \\
\hline Контрольная & $48(80,0 \%)$ & $12(12,0 \%)$ & $0(0 \%)$ & $108(90,0 \%)$ & $12(10,0 \%)$ & 10,534 \\
\hline Группа риска & $15(83,3 \%)$ & $2(11,1 \%)$ & $1(5,6 \%)$ & $32(88,9 \%)$ & $4(11,1 \%)$ & $\mathrm{p}=0,032 *$ \\
\hline Наркологические пациенты & $10(55,6 \%)$ & $8(44,4 \%)$ & $0(0,0 \%)$ & $28(77,8 \%)$ & $8(22,2 \%)$ & \\
\hline
\end{tabular}

П р и м е ч а н и е: *-уровень значимости $\mathrm{p}<0,05$.

Однако при попарном сравнении выявлено, что группа зависимых от ПАВ женщин отличалась лишь на уровне статистической тенденции от группы риска $\left(\chi^{2}=5,60, p=0,06\right)$ и от контрольной группы $\left(\chi^{2}=4,34, \mathrm{p}=0,11\right)$, при этом вычисленное значение отношение шансов для гетерозиготного генотипа AG полиморфного варианта rs6746030 гена SCN9A составило 6,40 (95\% Cl=1,12-36,44) при сравнении группы наркологических пациентов с группой риска и 3,20 $(95 \% \mathrm{Cl}=1,04-9,85)$ при сравнении с группой здоровых лиц.

Следующим этапом исследования было изучение ассоциации полиморфизма rs6746030 гена SCN9A с параметрами болевой чувствительности при формировании аддиктивной патологии. Показатели болевой чувствительности оценивались среди мужчин и женщин в сравниваемых группах в зависимости от носительства различных генотипов по полиморфному варианту rs6746030 гена SCN9A. Значения показателей нижнего и верхнего порогов у носителей разных генотипов исследуемого локуса статистически не различались ни в группе мужчин, ни в группе женщин.

Интересно, что в группе женщин с зависимостью от ПАВ показатель переносимости боли по ВАШ не только показал связь со стажем, но и на уровне статистической тенденции $\left(\chi^{2}=2,946, \mathrm{p}=0,086\right)$ был ас- социирован с генотипом полиморфного варианта rs6746030 гена SCN9A. Так, для генотипа АA данный показатель составил 6,0 (6,0-8,5), а для гетерозиготного генотипа AG он был ниже и составил 4,5 $(3,5-6,5)$, то у носителей генотипа AG чувствительность к боли была снижена (приведены значения Median - LQ; UQ). В то же время связи генотипов со стажем нет $\left(\chi^{2}=0,727,0,394\right)$, что позволяет предположить, что на эмоциональное восприятие боли узависимых от ПАВ женщин может влиять как стаж, так и их генетические особенности.

\section{ЗАКЛЮЧЕНИЕ}

В ходе проведенной работы было выявлено, что женщины из группы зависимых от ПАВ имеют менее выраженную фемининную направленность гендерной самоидентификации, чем женщины из контрольной группы здоровых лиц. В группе мужчин, зависимых от ПАВ, нижний болевой порог был значимо выше, чем в контрольной группе. Выявлено, что значения гендерного индекса и нижнего болевого порога взаимосвязаны, что выражалось в корреляции этих показателей в группе мужчин и в группе женщин с зависимостью от ПАВ. При этом для более высоких значений нижнего болевого порога было характерно снижение выраженности фемининности у женщин и маскулинности у мужчин. 
Полученные результаты свидетельствуют о том, что болевая чувствительность у зависимых от ПАВ лиц, возможно, связана со стажем употребления ПАВ. Так, стаж зависимости коррелировал со значениями нижнего болевого порога у мужчин и у женщин, а также с переносимостью боли в группе женщин. Одновременно с этим на болевую чувствительность при аддиктивных расстройствах могут влиять и генетические факторы. Так, на уровне статистической тенденции была выявлена ассоциация генотипа AG rs6746030 гена SCN9A с переносимостью боли и с развитием зависимости от ПАВ в группе женщин. Натриевый канал $\mathrm{NaV} 1.7$, кодируемый геном SCN9A, преимущественно экспрессируется в ноцицептивных первичных сенсорных нейронах, где он усиливает деполяризацию [12, 13, 14]. В ранних исследованиях было показано, что с изменением болевого порога была выявлена ассоциация аллеля А полиморфизма rs6746030 [15]. Тем самым полученные нами результаты согласуются с литературными данными и выдвинутой нами гипотезой о вкладе данного локуса в регуляцию механизмов боли при зависимости от ПАВ.

\section{КОНФЛИКТ ИНТЕРЕСОВ}

Авторы заявляют об отсутствии конфликта интересов в связи с публикацией данной статьи.

\section{ИСТОЧНИК ФИНАНСИРОВАНИЯ}

Исследование проведено при поддержке РФФИ проект № 17-36-01113-ОГН.

\section{СООТВЕТСТВИЕ ПРИНЦИПАМ ЭТИКИ}

Работа соответствует этическим стандартам Хельсинской декларации ВМА (протокол заседания этического комитета НИИ психического здоровья № 99 от 17 апреля 2017. Дело № 99/13.2017).

\section{ЛИТЕРАТУРА}

1. Семке В.Я., Бохан Н.А. Транскультуральная аддиктология. Томск : Изд-во Том. ун-та, 2008: 588

2. Чурин А.С., Сараева Е.В. Связь аддиктивного поведения с гендерными стереотипами у студентов. Конщепт. Научнометодический электронный журнал«2017; 29: 338-344. URL: http://e-koncept.ru/2017/770875.htm

3. Юрина А.С. Гендерная идентичность подростков, имеющих опыт употребления наркотических средств : автореф. дис. ... канд. психол. наук. СПб., 2008: 23.

4. Бохан Н.А., Янов С.А., Янова Г.В., Лившиц В.Л., Шин С. Гендерные различия в характере и последствиях употребле- ния алкоголя среди больных туберкулезом легких. Сибирский вестник психиатрии и наркологии. 2011; 5 (68): 34-37.

5. Fillingim R.B. Individual differences in pain responses. Curr Rheumatol Rep. 2005; 7 (5): 342-347.

6. Fillingim R.B., Wallace M.R., Herbstman D.M., Ribeiro-Dasilva M., Staud R. Genetic contributions to pain: a review of findings in humans. Oral Dis. 2008; 14 (8): 673-682.

7. Estacion M., Han C., Choi J.S., Hoeijmakers J.G.J., Lauria G., Drenth J.P.H., Gerrits M.M., Dib-Hajj S.D., Faber C.G., Merkies I.S.J., Waxman S.G. Intra- and interfamily phenotypic diversity in pain syndromes associated with a gain-of-function variant of NaV1.7. Mol Pain. 2011; 7: 92.

8. Reeder J.E., Byler T.K., Foster D.C., Landas S.K., Okafor H., Stearns G., Wood R.W., Zhang Y., Mayer R.D. Polymorphism in the SCN9A voltage-gated sodium channel gene associated with interstitial cystitis/bladder pain syndrome. Urology. 2013; 81(1): 210.e1-4.

9. Невидимова Т.И., Бохан Н.А., Коконова Д.Н. Способ количественной оценки индивидуальных болевых порогов. Патент 2342063 Российская Федерация; опубл. 27.12.2008. Бюл. № 36.

10. Collins S.L., Moore R.A., McQuay H.J. The visual analogue pain intensity scale: what is moderate pain in millimetres? Pain. 1997; 72: 95-97.

11. Вопросник Сандры Бем по изучению маскулинностифемининности: Практикум по гендерной психологии / под ред. И. С. Клециной. СПб., 2003: 277-280.

12. Toledo-Aral J.J., Moss B.L., He Z.J., Koszowski A.G., Whisenand T., Levinson S.R., Wolf J.J., Silos-Santiago I., Halegoua S., Mandel G. Identification of PN1, a predominant voltage-dependent sodium channel expressed principally in peripheral neurons. Proc Natl Acad Sci USA. 1997; 94 (4):15271532.

13. Djouhri L., Newton R., Levinson S.R., Berry C.M., Carruthers B., Lawson S.N. Sensory and electrophysiological properties of guinea-pig sensory neurones expressing Nav 1.7 (PN1) $\mathrm{Na}^{+}$ channel alpha subunit protein. J Physiol. 2003; 546 (Pt 2): 565576.

14. Holliday K.L, Thomson W., Neogi T., Felson D.T., Wang K., Wu F.C., Huhtaniemi I.T., Bartfai G., Casanueva F., Forti G., Kula K., Punab M., Vanderschueren D., Macfarlane G.J., Horan M.A., Ollier W., Payton A., Pendleton N., McBeth J. The nonsynonymous SNP, R1150W, in SCN9A is not associated with chronic widespread pain susceptibility. Mol Pain. 2012; 8: 72.

15. Reimann F., Cox J.J., Belfer I., Diatchenko L., Zaykin D.V., McHale D.P., Drenth J.P., Dai F., Wheeler J., Sanders F., Wood L., Wu T.X., Karppinen J., Nikolajsen L., Männikkö M., Max M.B., Kiselycznyk C., Poddar M., Te Morsche R.H., Smith S., Gibson D., Kelempisioti A., Maixner W., Gribble F.M., Woods C.G. Pain perception is altered by a nucleotide polymorphism in SCN9A. Proc Natl Acad Sci USA. 2010; 107 (11): 5148-5153.

Поступила в редакцию 27.04.2018 Утверждена к печати 6.11.2018

Савочкина Дарья Николаевна, кандидат медицинских наук, научный сотрудник лаборатории клинической психонейроиммунологии и нейробиологии.

Полтавская Евгения Григорьевна, научный сотрудник лаборатории молекулярной генетики и биохимии.

Савочкина Дарья Николаевна, kokodasha@yandex.ru

УДК 616.89-441.13:159.938.252:575.174.015.3:616-072.8

For citation: Savochkina D.N., Poltavskaya E.G. Assessment of psychophysiological characteristics and polymorphism of the gene SCN9A in the formation of addictive behavior. Siberian Herald of Psychiatry and Addiction Psychiatry. $2018 ; 4$ (101): 11-15. https://doi.org/10.26617/1810-3111-2018-4(101)-11-15

\section{Assessment of psychophysiological characteristics and polymorphism of the gene SCN9A in the formation of addictive behavior}




\section{Savochkina D.N., Poltavskaya E.G.}

Mental Health Research Institute, Tomsk National Research Medical Center, Russian Academy of Sciences Aleutskaya Street 4, 634014, Tomsk, Russian Federation

\section{ABSTRACT}

In this paper, the interrelationships of pain sensitivity indicators, gender identity and genetic characteristics of the examined persons at different stages of addictive behavior were analyzed. Materials and methods. The study included 248 persons: 108 patients with substance addiction, 34 persons from the risk group, 106 persons in the control group. Using the Sandra Bam questionnaire, a gender index was identified and a gender identity was identified. Thresholds of pain sensitivity and tolerability of pain were identified using our patented method of tensoalgometry. Genotyping of the polymorphic variant rs6746030 of the SCN9A gene was performed by real-time PCR using competing TaqMan probes. Results. Female persons with mental and behavioral disorders due to the use of psychoactive substances are characterized by the decrease in the severity of the feminine orientation of gender identity. The relationship between gender identity and pain sensitivity in substance dependent individuals is shown: for higher values of the lower pain threshold, a decrease in femininity in women and masculinity in men was characteristic. In the group of men dependent on psychoactive substances, the lower pain threshold was significantly higher than in the control group. The correlations of the lower pain threshold values with the dependency experience in men and women were revealed, as well as with the tolerability of pain in the group of women. Conclusion. At the level of a statistical trend, an association of the AG rs6746030 genotype SCN9A with pain tolerance and the development of dependence on psychoactive substances in a group of women was identified.

\section{Keywords: rs6746030 of SCN9A gene, pain sensitivity, gender identity, substance dependence.}

\section{REFERENCES}

1. Semke V.Ya., Bokhan N.A. Transcultural addictology. Tomsk: Publishing House of Tomsk University, 2008: 588.

2. Churin A.S., Saraeva E.V. Svyaz' addiktivnogo povedeniya s gendernymi stereotipami u studentov. [Connection of addictive behavior with gender stereotypes in students]. Kontsept. Nauchno-metodicheskiy elektronnyy zhurnal « Concept. Scientific and methodical electronic journal. 2017; 29: 338-344. URL: http://ekoncept.ru/2017/770875.htm (in Russian).

3. Yurina A.S. Gendernaya identichnost' podrostkov, imeyushchikh opyt upotrebleniya narkoticheskikh sredstv : avtoref. dis. ... kand. psikhol. nauk [Gender identity of adolescents with drug use: author. dis. ... kand. the course of studies. Sciences]. SPb., 2008: 23 (in Russian).

4. Bokhan N.A., Yanov S.A., Yanova G.V., Livshits V.L., Shin S Gender differences in character and consequences of alcohol use among patients with pulmonary tuberculosis. Sibirskii vestnik psikhiatrii i narkologii - Siberian Herald of Psychiatry and Addiction Psychiatry. 2011; 5 (68): 34-37.

5. Fillingim R.B. Individual differences in pain responses. Curr Rheumatol Rep. 2005; 7 (5): 342-347.

6. Fillingim R.B., Wallace M.R., Herbstman D.M., Ribeiro-Dasilva M., Staud R. Genetic contributions to pain: a review of findings in humans. Oral Dis. 2008; 14 (8): 673-682.

7. Estacion M., Han C., Choi J.S., Hoeijmakers J.G.J., Lauria G., Drenth J.P.H., Gerrits M.M., Dib-Hajj S.D., Faber C.G., Merkies I.S.J., Waxman S.G. Intra- and interfamily phenotypic diversity in pain syndromes associated with a gain-of-function variant of NaV1.7. Mol Pain. 2011; 7: 92.

8. Reeder J.E., Byler T.K., Foster D.C., Landas S.K., Okafor H., Stearns G., Wood R.W., Zhang Y., Mayer R.D. Polymorphism in the SCN9A voltage-gated sodium channel gene associated with interstitial cystitis/bladder pain syndrome. Urology. 2013; 81(1): 210.e1-4.

9. Nevidimova T.I., Bokhan N.A., Kokonova D.N. Method of quantitative assessment of individual pain thresholds. Patent 2342063 Russian Federation; published. 27.12.2008. Bull. No.
36. (in Russian)

10. Collins S.L., Moore R.A., McQuay H.J. The visual analogue pain intensity scale: what is moderate pain in millimetres? Pain. 1997; 72: 95-97.

11. Voprosnik Sandry Bem po izucheniyu maskulinnostifemininnosti: Praktikum po gendernoy psikhologii / pod red. I S. Kletsinoy [Sandra Bam Questionnaire on study of masculinity-femininity. Practicum on gender psychology. I.S. Kletsina, ed] SPb., 2003: 277-280 (in Russian).

12. Toledo-Aral J.J., Moss B.L., He Z.J., Koszowski A.G., Whisenand T., Levinson S.R., Wolf J.J., Silos-Santiago I., Halegoua S., Mandel G. Identification of PN1, a predominant voltage-dependent sodium channel expressed principally in peripheral neurons. Proc Natl Acad Sci USA. 1997; 94 (4):15271532 .

13. Djouhri L., Newton R., Levinson S.R., Berry C.M., Carruthers B., Lawson S.N. Sensory and electrophysiological properties of guinea-pig sensory neurones expressing Nav 1.7 (PN1) $\mathrm{Na}^{+}$ channel alpha subunit protein. J Physiol. 2003; 546 (Pt 2): 565576.

14. Holliday K.L, Thomson W., Neogi T., Felson D.T., Wang K., Wu F.C., Huhtaniemi I.T., Bartfai G., Casanueva F., Forti G., Kula K., Punab M., Vanderschueren D., Macfarlane G.J., Horan M.A., Ollier W., Payton A., Pendleton N., McBeth J. The nonsynonymous SNP, R1150W, in SCN9A is not associated with chronic widespread pain susceptibility. Mol Pain. 2012; 8: 72.

15. Reimann F., Cox J.J., Belfer I., Diatchenko L., Zaykin D.V., McHale D.P., Drenth J.P., Dai F., Wheeler J., Sanders F., Wood L., Wu T.X., Karppinen J., Nikolajsen L., Männikkö M., Max M.B., Kiselycznyk C., Poddar M., Te Morsche R.H., Smith S., Gibson D., Kelempisioti A., Maixner W., Gribble F.M., Woods C.G. Pain perception is altered by a nucleotide polymorphism in SCN9A. Proc Natl Acad Sci USA. 2010; 107 (11): 5148-5153.

Received April 27.2018 Accepted November 6.2018

Savochkina Dariya N., PhD, researcher at the Laboratory of Clinical Psychoneuroimmunology and Neurobiology, Mental Health Research Institute, Tomsk National Research Medical Center, Russian Academy of Sciences, Tomsk, Russian Federation.

Poltavskaya Evgenia G., researcher, Laboratory of Molecular Genetics and Biochemistry, Mental Health Research Institute, Tomsk National Research Medical Center, Russian Academy of Sciences, Tomsk, Russian Federation. 